\title{
Internal common carotid artery stenosis in concomitant with subclavian artery occlusion in a young lady with Takayasu syndrome
}

\author{
Azin alizadehasl ${ }^{1}$, Leila Najmafshar ${ }^{2}$, and Hamidreza Pouraliakbar ${ }^{2}$ \\ ${ }^{1}$ Rajaie Cardiovascular Medical and Research Center \\ ${ }^{2}$ Shaheed Rajaei Cardiovascular Medical and Research Center
}

September 14, 2020

\begin{abstract}
Takayasu arteritis is a chronic vasculitis that affects large vessels and causes focal or diffuse thickening of the vessel walls with consequent stenosis, occlusion, or thrombosis. Here, we describe a young lady with Takayasu, which had Internal common carotid artery stenosis and subclavian artery occlusion with focusing on the value of transthoracic echocardiography (2D) in the diagnosis of these complications of Takayasu.
\end{abstract}

\section{KEY WORDS}

Takayasu, common carotid artery stenosis, subclavian artery occlusion, transthoracic echocardiography

A 36 year old female presented with saddle nose, urticaria and dyspnea. She was undertreatment for 4 years with Asthma diagnosis. Also she complained from intermittent claudication in her left arm that kept worsening gradually. Due to dyspnea and pulselessness in her left arm, a transthoracic echocardiogram (TTE) was performed and revealed: mild LV enlargement with severe systolic dysfunction (GEF=15-20\%)with no obvious clot, mild to moderate MR, Thickened tricuspid AV,mild to moderate AI,Thoracic descending and abdominal aortic flow had normal flow pattern. Ascending aorta had normal size with turbulent flow at origin of left carotid artery with increased velocity $=3.6 \mathrm{~cm} / \mathrm{sec}$, with antegrade diastolic flow suggestive of significant stenosis, left subclavian artery flow was not seen due to obstraction. There was systolic turbulent flow at proximal of descending aorta $(\mathrm{PG}=25 \mathrm{mmHg})$ with no antegrade diastolic flow suggestive of mild narrowing of descending aorta with no significant stenosis. In CT angiography Thoracic aorta showed thickened wall and severe calcification.Left common carotid artery showed severe stenosis at origin.Left subclavian artery was cut off from origin and run off before the origin of vertebral artery (yellow arrow).Left distal subclavian and axillary artery fill via vertebral artery.Calcification of abdominal aorta with mild ectatic lumen in infrarenal portion was seen.

Angiography revealed that left internal carotid artery had significant stenosis (80\%) ostial-proximal narrowing with good run off; and left subclavian artery was totally occluded. Due to unexplained left ventricular dysfunction, CMR was performed and according to CMR finding, localized basal inferolateral LV edma and patchy myocardial fibrosis in favor of acute myocarditis was seen.

She candidate to invasive methods but unfortunately refused. Diuretics, cellcept and prednisolone were initiated and her discomforts slightly improved.

\section{References}


1. Otto, Catherine M: The practice of echocardiography. Fifth edition. Echocardiographic findings in Systemic Diseases Characterized by Immune-Mediated Injury, 2017, p: 713-715.

2. Dong H, Jiang X, Peng M, et al.: Percutaneous transluminal angioplasty for symptomatic pulmonary stenosis in Takayasu arteritis, J Rheumatol 41:1856-1862, 2014.
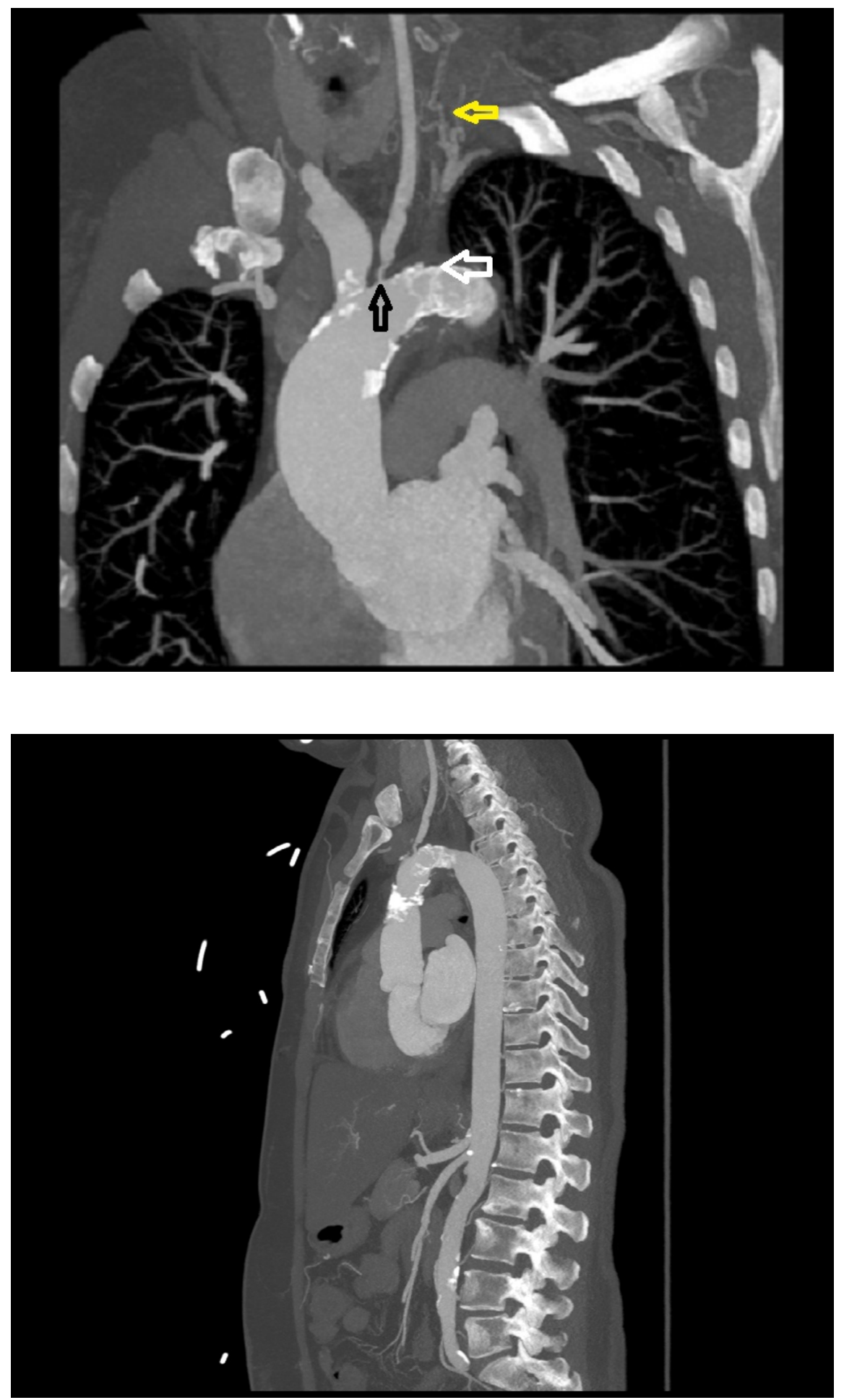


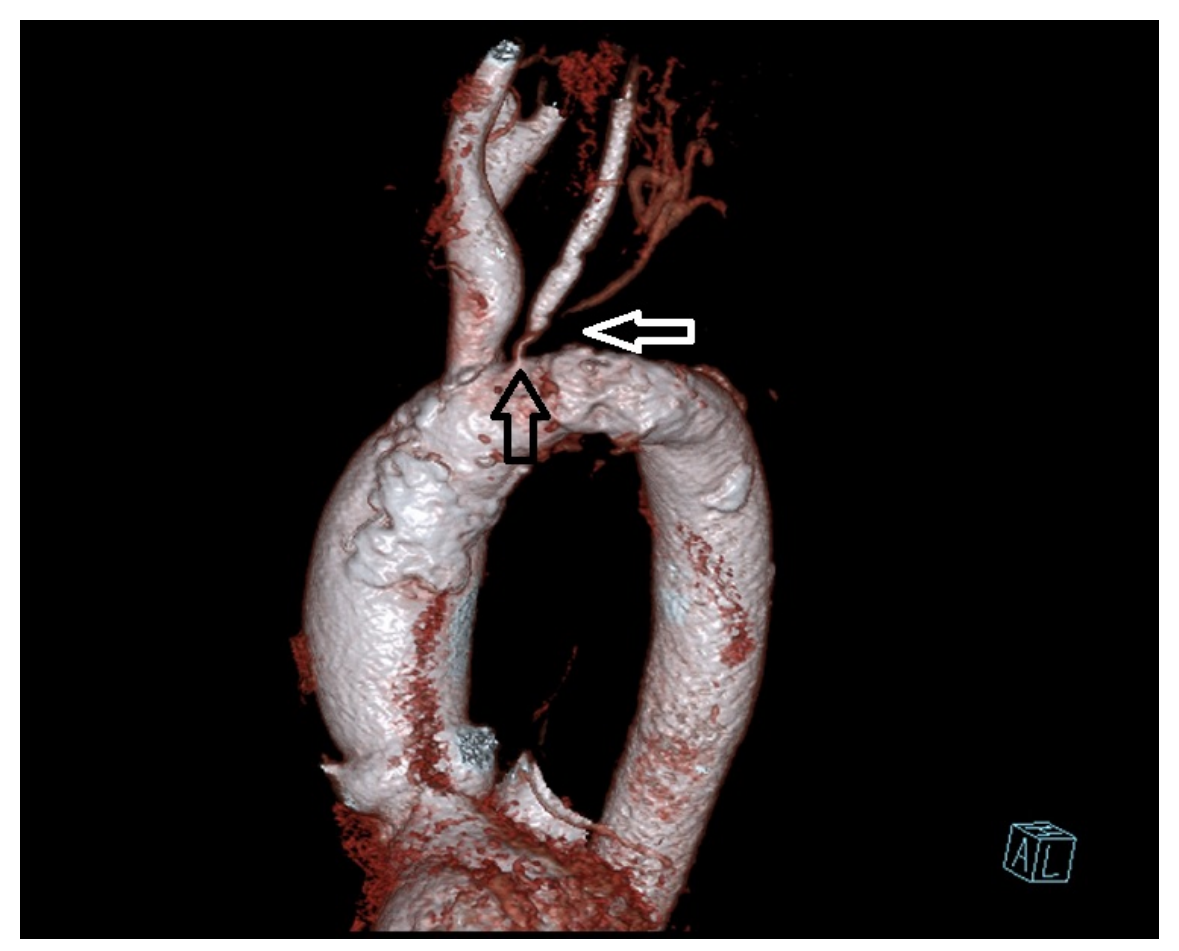

\section{Hosted file}

TAK 6_x264.mp4 available at https://authorea.com/users/318927/articles/480675-internalcommon-carotid-artery-stenosis-in-concomitant-with-subclavian-artery-occlusion-in-ayoung-lady-with-takayasu-syndrome

\section{Hosted file}

TAK 3_x264.mp4 available at https://authorea.com/users/318927/articles/480675-internalcommon-carotid-artery-stenosis-in-concomitant-with-subclavian-artery-occlusion-in-ayoung-lady-with-takayasu-syndrome 